\section{Comportamento das doenças diarréicas agudas em serviços de saúde de Fortaleza, Ceará, Brasil, entre 1996 e 2001}

\author{
Acute diarrhea treated by health care \\ services in Fortaleza, Ceará State, \\ Brazil, from 1996 to 2001
}

Mônica Cardoso Façanha 1,2 Alicemaria Ciarlini Pinheiro 2

\title{
Introdução
}

1 Universidade Federal do Ceará, Fortaleza, Brasil. 2 Coordenadoria de Políticas de Saúde, Secretaria Municipal de Saúde, Fortaleza, Brasil.

\section{Correspondência} M. C. Façanha Universidade Federal do Ceará. Rua Pinto Madeira 777, apto. 701, Fortaleza, CE 60150-000, Brasil. mfacanha@ufc.br mfacanha@yahoo.com

\begin{abstract}
Diarrhea is still an important cause of morbidity and mortality among children under five years old. It is not mandatory to report diarrheal diseases, and the statistics are not accurate. The objective of this study was to describe follow-up of acute diarrhea in Fortaleza, the capital of Ceará State, Brazil. From 1994 to 2001, cases of acute diarrhea were reported by 100 health care units using a standardized form, keyed-in and analyzed by month, age group, treatment plan, place of treatment, and place of residence. There were 489,069 cases reported, with an annual average of 81,511. February and March had the highest monthly rates. Incidence in infants $(<1$ year) was 538.8, three times that of children from 1 to 4 years and 13 times the rate in the 5-to-9-year bracket. All areas in the city reported cases of diarrhea. Diarrhea shows a persistently high incidence, mainly among infants, and merits attention as a major public health problem.
\end{abstract}

Infantile Diarrhea; Infant Mortality; Child Health
Cerca de dois milhões de crianças morrem a cada ano nos países subdesenvolvidos em conseqüência de doenças diarréicas, segunda maior causa de morte em crianças com menos de cinco anos de idade. As complicações mais freqüentes decorrem da desidratação e desequilíbrio hidroeletrolítico. A médio e longo prazos, a repetição dos episódios de diarréia pode levar à desnutrição crônica, com retardo do desenvolvimento ponderal e, até mesmo, da evolução intelectual 1 .

Em torno de um milhão e oitocentas mil vidas poderiam ser salvas (mais de 90,0\%), uma vez que a diarréia pode ser prevenida ou tratada 2. O coeficiente de mortalidade infantil por diarréia no Brasil apresentou declínio nas últimas décadas. Em Salvador, Bahia, houve redução de 25,9\% em 1977 para 2,1\% em 1998. Essa redução de 91,9\% estaria associada a intervenções sanitárias e à terapia de reidratação oral 3. No ano 2000, o coeficiente de mortalidade infantil em Fortaleza, Ceará, foi de 23,3 por mil nascidos vivos e por diarréia foi de 0,95.

Em países desenvolvidos a freqüência de quadros diarréicos em lactentes é de apenas 0,5 a 2 episódios/ano, enquanto que nas regiões em desenvolvimento pode chegar a 104 . Na cidade de São Paulo em 1995/1996, a incidência já havia alcançado um episódio/criança/ano, número que se aproxima daqueles dos 
países desenvolvidos 5 . No ano 2000 , em comunidades urbanas de baixa renda de Olinda e Recife, Pernambuco, a incidência anual corrigida e estimada a partir da incidência em 15 dias foi de 2,7 episódios/criança/ano 6. Estudos de coorte mostram a incidência de 4 a 6 episódios por ano em crianças que vivem em condições desfavoráveis. As diarréias representam a segunda maior causa de consulta médica, precedida apenas pelas doenças respiratórias agudas. Representam cerca de $30,0 \%$ a $40,0 \%$ das consultas ao gastroenterologista 7 .

A associação do aumento do índice de contaminação bacteriológica de águas de poços do lençol freático superficial esta associada com as chuvas 8 . Essa piora da qualidade da água estaria associada ao escoamento das águas da chuva carreando excretas humanos e animais. O uso dessa água não tratada aumentaria a freqüência de diarréias no período chuvoso.

As diarréias não fazem parte do elenco de doenças de notificação compulsória nacionais. Isso torna os números das diarréias ainda pouco conhecidos no Brasil 9.

Com o advento da epidemia de cólera em 1991 no Peru, tornou-se necessário o conhecimento do comportamento das diarréias agudas, para que sua mudança servisse como indicador para detecção precoce da introdução da cólera em uma determinada região geográfica. Para isso, era necessário observar seu comportamento também em adultos, uma vez que são os adultos os primeiros acometidos quando a cólera é introduzida em uma área. Para essa observação, era necessário que houvesse mudanças na forma de acompanhar a ocorrência dessas doenças 9,10. Os instrumentos de registro dos casos foram revisados, adequados e padronizados para todo o país. Para a implantação desses formulários o Ministério da Saúde confeccionou módulos de treinamento que foram aplicados em Fortaleza, em 1994 e 1995.

As evoluções que esses formulários implementaram foram a introdução da faixa etária de maiores de dez anos de idade, a informação por plano de tratamento, por local de residência e uma análise dirigida para a detecção de surtos de diarréia. As pessoas responsáveis pelo preenchimento dos formulários deveriam comparar as informações da semana atual com as da semana anterior, e informar se tinha havido aumento no número de casos, se o aumento tinha sido em uma faixa etária ou região geográfica determinada e se tinha ocorrido maior número de casos com desidratação grave. Além disso, passou a sugerir a conduta para o diagnóstico etiológico e de fonte da infecção, como também para o controle do surto 9,10. Desta for- ma, a análise dos casos de diarréia é mais específica quando feita na menor unidade de saúde do que quando é feita em nível central.

O objetivo deste estudo é descrever a distribuição das doenças diarréicas agudas por mês e ano, sua relação com os índices de pluviosidade, incidência por faixa etária e o plano de tratamento utilizado em unidades de saúde públicas.

\section{Material e métodos}

O dados apresentados neste estudo são o resultado das informações semanais de cem unidades de saúde, enviadas às Secretarias Executivas Regionais e, depois de sua consolidação, remetidas à Célula de Vigilância Epidemiológica da Secretaria Municipal de Saúde de Fortaleza, no período de 1996 a 2001. Os dados foram analisados através do Epi Info 6.04.

Para fins de vigilância epidemiológica, diarréia aguda foi definida como o aumento do volume da água fecal, o que acarreta diminuição na consistência das fezes e aumento no número de evacuações e com duração de até duas semanas 7 .

Foi considerado como tendo usado o plano A de tratamento aquele paciente que recebeu prescrição de líquidos caseiros no domicílio, o que corresponde à ausência de sinais de desidratação. O plano B quando o doente precisou fazer uso de sais de reidratação oral, sob supervisão na unidade de saúde, para que se avaliasse se esse tratamento seria suficiente para evitar complicações. Esse tratamento é indicado para pessoas com algum sinal de desidratação. E, o plano $\mathrm{C}$ quando houve indicação de reidratação venosa, isto é, em pacientes com desidratação severa 9 .

Todas as unidades de saúde públicas e conveniadas do Sistema Único de Saúde (SUS), hospitalares e ambulatoriais informaram seus atendimentos nos serviços de urgência e nos ambulatórios. As clínicas particulares não informaram seus atendimentos. Estima-se que 70,0\% da população de Fortaleza seja atendida nesses serviços.

Foram treinados profissionais das seis regiões administrativas em que Fortaleza encontra-se dividida, denominadas Secretarias Executivas Regionais (SER), de todas as unidades ambulatoriais que atendiam diarréias, de todos os hospitais públicos municipais e de hospitais conveniados do SUS com serviço de emergência. Além da notificação e monitorização dos casos de diarréia, o treinamento também teve como objetivos padronizar a defini- 
ção de caso, a avaliação de grau de desidratação, o tratamento e a intervenção para o controle de surtos. A informação passou a ser semanal para que houvesse tempo hábil de implementar medidas de controle.

Para o cálculo de incidência foi utilizado como numerador o número de pacientes com um episódio de doença diarréica aguda dividido por mil habitantes do Município de Fortaleza, no ano de ocorrência da doença que o levou a procurar assistência médica. A população utilizada para o cálculo de incidência de episódios de diarréia foi a estimada pelo IBGE (Instituto Brasileiro de Geografia e Estatítica) baseada no censo de 2001. Os índices pluviométricos foram informados pela Fundação Cearense de Meteorologia (FUNCEME).

\section{Resultados}

No período de 1996 a 2001 foram informados 489.069 casos de doenças diarréicas agudas, com média anual de 81.511,5 (DP = 9.169) de notificações (Tabela 1). Os primeiros meses do ano, especialmente fevereiro e março, apresentaram médias mais altas que as observadas no segundo semestre, mais especificamente a partir de junho. A proporção de pacientes com registro de atendimento no primeiro semestre foi maior do que a registrada no segundo $(\mathrm{p}<0,01)$. Quando se compara a média mensal de pluviosidade com a incidência de diarréias agudas, observase uma associação temporal entre a intensidade das chuvas e o número de casos (Figura 1).
A distribuição dos casos de doenças diarréicas agudas por faixa etária manteve-se aproximadamente estável. Isto é, as crianças entre 1 e 4 anos foram as mais representadas, seguidas pelas menores de um ano. A pessoas com dez anos e mais de idade ficaram em terceiro lugar e em quarto os que tinham entre 5 e 9 anos (Tabela 2). Considerando-se a incidência de episódios de diarréia, a dos menores de um ano foi 3,8 vezes maior do que os de 1 a 4 anos e 13,5 vezes maior do que os de 5 a 9 anos. Entre 1996 e 2001, a média de incidência de episódios de diarréia em menores de um ano foi de 538,8 casos por cada mil menores de um ano, 150,2 por mil crianças entre 1 e 4 anos, 40,7 por mil de 5 a 9 anos e 10,6 para cada mil pessoas com dez ou mais anos de idade. O risco dos menores de um ano de adoecerem (ou de serem levados às unidades públicas de saúde por diarréia) é 3,59 vezes maior do que o das crianças de 1 a 4 anos (IC95\%: 3,52-3,65). Em relação às de 5 a 9 anos, o risco dos menores de um ano é 10,93 vezes maior (IC95\%: 10,63-11,24). $\mathrm{O}$ risco de crianças maiores de dez anos e adultos é 46,59 vezes menor (IC95\%: 45,59-47,66) de ser atendido por diarréia numa unidade pública de saúde do que os menores de um ano.

Mais da metade do total de pacientes $(65,0 \%)$ foi tratada com o plano A. Em torno de $20,0 \%$ dos pacientes precisaram ficar em observação na unidade de saúde recebendo soro de reidratação oral (plano B). Cerca de 12,0\% tiveram indicação de reidratação venosa (plano C). Em 1,8\% não se obteve a informação sobre que tratamento havia sido administrado aos pacientes (Tabela 3).

Casos de diarréias agudas por ano e mês. Fortaleza, Ceará, Brasil, 1996-2001.

\begin{tabular}{|c|c|c|c|c|c|c|c|}
\hline Mês & 1996 & 1997 & 1998 & 1999 & 2000 & 2001 & Total \\
\hline Janeiro & 8.248 & 4.998 & 6.517 & 7.469 & 8.408 & 5.448 & 41.088 \\
\hline Fevereiro & 9.168 & 5.563 & 8.366 & 11.424 & 11.589 & 7.129 & 53.239 \\
\hline Março & 10.544 & 8.916 & 7.387 & 15.318 & 9.051 & 7.653 & 58.869 \\
\hline Abril & 9.778 & 6.901 & 6.640 & 10.251 & 5.374 & 7.491 & 46.435 \\
\hline Maio & 8.599 & 8.332 & 6.024 & 8.198 & 5.892 & 8.044 & 45.089 \\
\hline Junho & 5.824 & 6.748 & 4.875 & 8.305 & 6.405 & 8.774 & 40.931 \\
\hline Julho & 6.344 & 3.845 & 5.860 & 5.700 & 5.825 & 6.361 & 33.935 \\
\hline Agosto & 5.698 & 3.580 & 5.241 & 4.845 & 5.933 & 6.220 & 31.517 \\
\hline Setembro & 5.444 & 5.232 & 6.776 & 6.806 & 6.636 & 6.715 & 37.609 \\
\hline Outubro & 6.687 & 4.161 & 5.248 & 5.738 & 4.859 & 6.050 & 32.743 \\
\hline Novembro & 5.130 & 4.627 & 5.979 & 5.846 & 5.076 & 5.892 & 32.550 \\
\hline Dezembro & 4.548 & 6.606 & 5.665 & 6.784 & 4.671 & 6.790 & 35.064 \\
\hline Total & 86.012 & 69.509 & 74.578 & 96.684 & 79.719 & 82.567 & 489.069 \\
\hline
\end{tabular}


Figura 1

Incidência de doenças diarréicas agudas e pluviosidade. Fortaleza, Ceará, Brasil, 1996-2001.

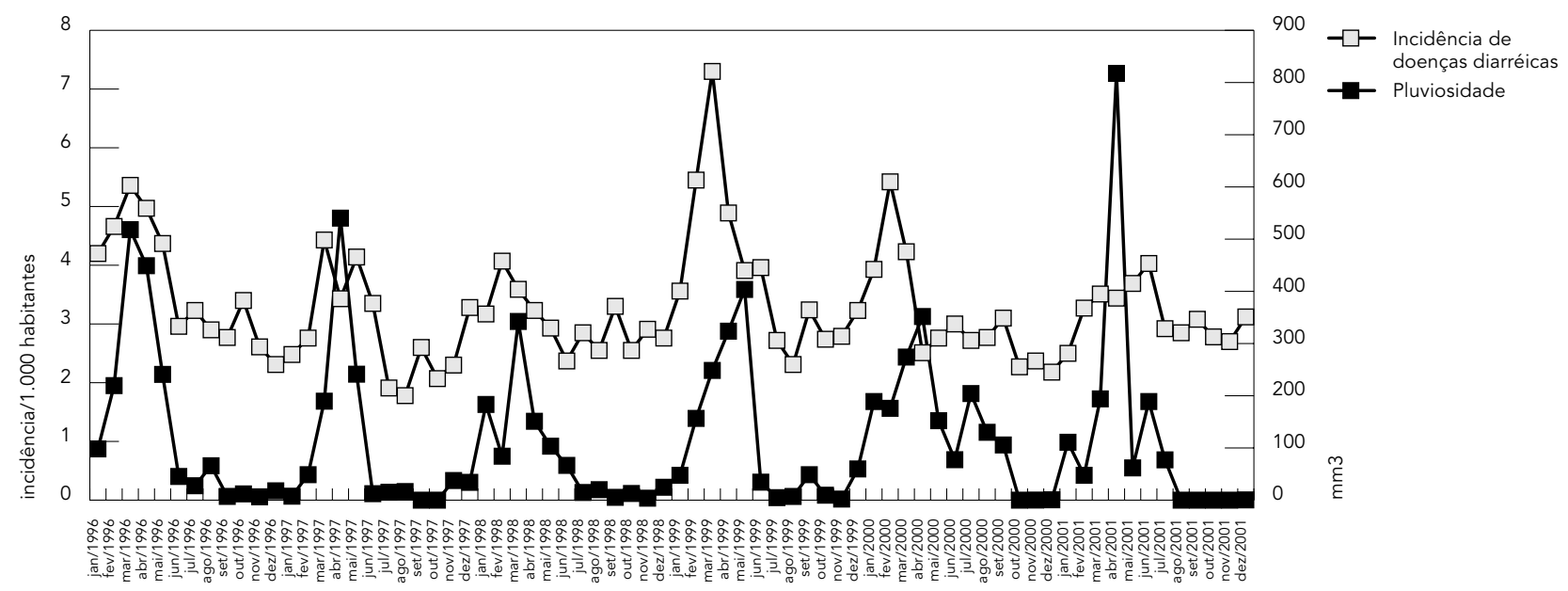

Fonte: Célula de Vigilância Epidemiológica, Coordenadoria de Políticas de Saúde, Secretaria Municipal

de Saúde/Fundação Cearense de Metereologia.

Tabela 2

Casos e incidência* de diarréias agudas por ano e faixa etária. Fortaleza, Ceará, Brasil, 1996-2001.

\begin{tabular}{|c|c|c|c|c|c|c|c|c|c|c|c|c|}
\hline \multirow{2}{*}{$\begin{array}{l}\text { Faixa etária } \\
\text { (em anos) }\end{array}$} & \multicolumn{2}{|c|}{1996} & \multicolumn{2}{|c|}{1997} & \multicolumn{2}{|c|}{1998} & \multicolumn{2}{|c|}{1999} & \multicolumn{2}{|c|}{2000} & \multicolumn{2}{|c|}{2001} \\
\hline & Casos & Incidência & Casos & Incidência & Casos & Incidência & Casos & Incidência & Casos & Incidência & Casos & Incidência \\
\hline$<1$ & 28.223 & 676,9 & 22.607 & 527,6 & 20.637 & 468,6 & 25.531 & 574,0 & 21.704 & 492,5 & 22.153 & 493,0 \\
\hline $1-4$ & 30.706 & 162,6 & 27.569 & 142,1 & 27.615 & 138,5 & 35.790 & 179,4 & 27.779 & 139,2 & 28.376 & 139,4 \\
\hline $5-9$ & 9.186 & 38,6 & 7.370 & 30,4 & 8.703 & 34,9 & 12.049 & 47,4 & 10.452 & 41,9 & 11.998 & 47,2 \\
\hline $10 \mathrm{e}+$ & 16.337 & 10,5 & 11.259 & 7,0 & 16.231 & 9,9 & 22.431 & 13,5 & 18.822 & 11,4 & 18.669 & 11,1 \\
\hline
\end{tabular}

* Incidência por 1.000 habitantes.

Tabela 3

Casos de diarréias agudas por ano e plano de tratamento. Fortaleza, Ceará, Brasil, 1996-2001.

\begin{tabular}{|c|c|c|c|c|c|c|c|c|c|c|c|c|}
\hline \multirow{2}{*}{$\begin{array}{l}\text { Plano de } \\
\text { tratamento* }\end{array}$} & \multicolumn{2}{|c|}{1996} & \multicolumn{2}{|c|}{1997} & \multicolumn{2}{|c|}{1998} & \multicolumn{2}{|c|}{1999} & \multicolumn{2}{|c|}{2000} & \multicolumn{2}{|c|}{2001} \\
\hline & Casos & $\%$ & Casos & $\%$ & Casos & $\%$ & Casos & $\%$ & Casos & $\%$ & Casos & $\%$ \\
\hline$A$ & 56.725 & 67,0 & 45.435 & 66,2 & 47.742 & 64,4 & 63.550 & 65,8 & 52.237 & 65,6 & 50.752 & 62,0 \\
\hline B & 16.903 & 20,0 & 15.401 & 22,4 & 14.447 & 19,5 & 18.659 & 19,3 & 15.498 & 19,5 & 18.249 & 22,3 \\
\hline C & 11.078 & 13,1 & 7.833 & 11,4 & 11.965 & 16,1 & 14.356 & 14,9 & 11.837 & 14,9 & 12.820 & 15,7 \\
\hline
\end{tabular}

Fonte: Célula de Vigilância Epidemiológica, Coordenadoria de Políticas de Saúde, Secretaria Municipal de Saúde de Fortaleza.

* Planos de tratamento: $A=$ tratamento domiciliar com líquidos caseiros; $B=$ reidratação com soro de reidratação oral

sob supervisão na unidade de saúde; $C$ = reidratação venosa. 


\section{Discussão}

A diarréia continua sendo um importante motivo de procura das unidades de saúde para assistência médica. De fevereiro a maio costuma ser o período do ano mais chuvoso no Município de Fortaleza. Nesse período as doenças respiratórias também acontecem com maior freqüência. O aumento no número de casos de diarréia, logo depois dos picos de pluviosidade, pode estar associado à ingestão de águas de fontes diferentes das habituais, à contaminação do lençol freático por fossas sépticas ou à circulação de outros agentes etiológicos.

Apesar da grandeza dos números informados, existe a limitação da falta de universalidade, quando dados são analisados com base em procura espontânea dos serviços de saúde 11 . Ainda há subnotificação, os casos de diarréias atendidos em clínicas e consultórios particulares não são comunicados, o que sugere que essa não deve ser a única fonte de informação sobre a ocorrência de diarréias a ser utilizada numa área com esses problemas de subnotificação e ainda mais porque é uma doença autolimitada. Com esse montante de casos informados, há necessidade de alocação de número de consultas médicas, número de profissionais e de insumos para o atendimento dessa população, especialmente das crianças menores, que superlotam as unidades de saúde e emergências.

A incidência foi calculada considerando toda a população, embora se saiba que a de maior renda não procura as unidades de saúde públicas e que crianças maiores e adultos, muitas vezes, se automedicam, não comparecendo à unidade de saúde. Considerando as faixas etárias dessa coleta de dados, observou-se que de uma faixa etária para a seguinte o decréscimo foi de cerca de 3,7 vezes. Em 1994, a incidência de diarréia entre crianças de 1 a 4 anos foi tão elevada quanto a de menores de um ano, possivelmente em decorrência da epidemia de cólera, que teve grandes proporções em Fortaleza entre 1992 e 1994.
Em virtude dos formulários de coleta de dados terem sido formatados com faixas etárias fixas, não foi possível separar as idades para análise mais detalhada daquelas pessoas com dez anos e mais de idade, embora a inclusão dessa faixa etária tenha representado uma evolução em relação ao conhecimento dos casos de diarréia tratados nas unidades de saúde públicas.

A proporção de utilização de cada um dos planos de tratamento tem se mantido estável ao longo dos anos. Este é um dos parâmetros utilizados para avaliação da introdução da cólera. Quando a cólera é introduzida, espera-se que ocorra mais desidratação e maior utilização de hidratação venosa, aplicação do plano $\mathrm{C}$ de tratamento. Vale salientar que, depois da introdução da monitorização das diarréias, os surtos de cólera tornaram-se muito escassos, não tendo sido possível testar a sensibilidade da monitorização das diarréias agudas para sua detecção. O fato da maioria dos casos informados ter sido tratado com o plano A, sugere que esses pacientes estão chegando para o atendimento ainda sem desidratação. Apenas para $14,0 \%$ dos casos informados foi indicada a hidratação venosa.

As diarréias têm alta incidência em todas as regiões da cidade, entretanto, são mais freqüentes nas áreas mais pobres. Possivelmente por terem maior incidência real nessas áreas, mas também porque as pessoas de menor poder aquisitivo procuram mais as unidades públicas de saúde para o atendimento, e essas são as principais fontes de informação sobre os números das doenças diarréicas agudas.

\section{Conclusão}

As diarréias continuam sendo muito freqüentes, acometem principalmente as crianças menores de cinco anos, têm levado os pacientes para o atendimento antes de apresentarem desidratação grave e têm relação temporal com as chuvas. 


\section{Resumo}

Diarréias ainda são importantes causas de mortalidade e morbidade entre as crianças menores de cinco anos de idade. Não são doenças de notificação compulsória e seus números são pouco conhecidos. O objetivo deste estudo é descrever o comportamento das diarréias agudas em Fortaleza, Ceará, Brasil. Entre 1996 e 2001, cem unidades de saúde notificaram diarréias agudas por meio de um formulário padronizado, digitado e analisado por mês, faixa etária, plano de tratamento, local de atendimento e residência. Foram informados 489.069 casos, com 81.511,5 de média anual. Os meses de fevereiro e março tiveram maior número de casos. A incidência em menores de um ano foi de 538,8, três vezes maior do que naqueles de 1 a 4 anos e 13 vezes maior do que nos de 5 a 9 anos. As diarréias continuam com alta incidência, principalmente entre as crianças menores de um ano, merecendo atenção como problema de saúde pública de grande magnitude.

Diarréia Infantil; Mortalidade Infantil; Saúde Infantil

\section{Colaboradores}

O planejamento do estudo e análise dos dados foram conjuntos. M. C. Façanha ficou responsável pela elaboração das planilhas para consolidar informações, elaboração de gráficos e análises preliminares, bem como pela apresentação e discussão periódica dos relatórios parciais. A. C. Pinheiro ficou responsável pelo acompanhamento das unidades notificantes e recebimento dos relatórios das Secretarias Executivas Regionais.

\section{Agradecimentos}

À Mariana Lopes Bento, responsável pela digitação e acompanhamento das diarréias na Secretaria Municipal de Saúde de Fortaleza e às equipes de Vigilância Epidemiológica das Secretarias Executivas Regionais e Unidades de Saúde que coletam e compilam os casos em seus locais de atuação.

\section{Referências}

1. Niehaus MD, Moore SR, Patrick PD, Derr L, Lorntz B, Lima AA, Guerrant RL. Early childhood diarrhea is associated with diminished cognitive function 4 to 7 years later in children in a northeast Brazilian shantytown. Am J Trop Med Hyg 2002; 66:590-3.

2. World Health Organization. Reducing mortality from major killing of children. Fact sheet 178. http://www.who.int/inf-fs/en/fact178.html (acessado em 18/Mar/2002).

3. Guimarães ZA, Costa MCN, Paim JS, Silva LMV. Declínio e desigualdades sociais na mortalidade infantil por diarréia. Rev Soc Bras Med Trop 2001; 34:473-8.

4. Guerrant RL, Hughes JM, Lima NL, Crane J. Diarrhea in developed and developing countries: magnitude, special setting and etiologies. Rev Infect Dis 1990; 12 Suppl 1:S41-50.

5. Benício MHA, Monteiro CA. Tendência secular da doença diarréica na cidade de São Paulo (19841996). Rev Saúde Pública 2000; 34:83-90.

6. Vasques ML, Mosquera M, Cuevas LE, Gonzalez ES, Versa ICL, Luz EO, et al. Incidência e fatores de risco de diarréia e infecções respiratórias agudas em comunidades urbanas de Pernambuco,
Brasil. Cad Saúde Publica 1999; 15:163-72.

7. Martins EB. Diarréias. In: Schechter M, Marangoni DV, organizadores. Doenças infecciosas. Conduta diagnóstica e terapêutica. 2a Ed. Rio de Janeiro: Guanabara Koogan; 1998. p. 263-71.

8. Amaral LA, Nader Filho A, Rossi Jr. OD, Ferreira FL, Barros LS. Drinking water in rural farms as a risk factor to human health. Rev Saúde Pública 2003; 37:510-4.

9. Ministério da Saúde. Diarréias agudas, aspectos epidemiológicos. http://www.funasa.gov.br/guia epi/htm/doencas/diarreia/index.htm (acessado em 18/Mar/2002).

10. Ministério da Saúde. Cólera. In: Guia de vigilância epidemiológica. 2a Ed. Brasília: Fundação Nacional de Saúde; 2002. p. 145-65.

11. Bittencourt AS, Leal MC, Santos MO. Hospitalizações por diarréia infecciosa no Estado do Rio de Janeiro. Cad Saúde Pública 2002; 18:747-54.

Recebido em $01 / \mathrm{Jul} / 2002$

Versão final reapresentada em 11/Mar/2004

Aprovado em 13/Jul/2004 